\title{
OPERATOR 5.0: A SURVEY ON ENABLING TECHNOLOGIES AND A FRAME- WORK FOR DIGITAL MANUFACTURING BASED ON EXTENDED REALITY
}

\begin{abstract}
The industrial landscape is undergoing a series of fundamental changes, because of the advances in cutting-edge digital technologies. Under the framework of Industry 4.0 engineers have focused their effort on the development of new frameworks integrating digital technologies such as Big Data Analytics, Digital Twins, Extended Reality, and Artificial Intelligence, to upscale modern manufacturing systems, reduce uncertainties, and cope with the increased market volatility. However, in the upcoming industrial revolution, i.e., Industry 5.0, the research focus will be directed towards the new generation of human operators, the Operator 5.0. The purpose of this paper is to investigate the key technologies that will be the drivers towards the realization of the Operator 5.0 and to highlight the key challenges. Additional contribution is the proposal of a framework for the training and support of shopfloor technicians based on the utilization of Mixed Reality for manufacturing processes.
\end{abstract}

\section{INTRODUCTION}

Several technological advances fuelled the industrialization of society in various countries during the late 19th and early 20th centuries. More specifically, electrification, petrochemical development, rail transportation expansion, and metallurgical industry advancements were among the many innovations. In the manufacturing sector, the birth of mass production was a major paradigm shift $[1,2]$. Henry Ford was a pioneer and promoter of Mass Production (MP) [3]. The most significant contribution of MP was the establishment of assembly lines as the central axis of the automobile manufacturing process, as well as the adoption of standardization as a fundamental production principle [4]. An assembly line is a continuous flow of workpieces created by an industrial arrangement of machines, equipment, and technicians [5]. Since the establishment of MP paradigm, assembly lines and manufacturing in general have greatly evolved. Outside of the automotive industry, this type of production organization has spread to a wide range of industries. Furthermore, since the second half of the twentieth century, the development of industrial robotics has resulted in a significant increase in automation and customization levels. Industry 4.0 takes automation to the next level by incorporating digital technologies such as the Internet of Things (IoT),

\footnotetext{
${ }^{1}$ Department of Mechanical Engineering and Aeronautics, University of Patras, Laboratory for Manufacturing Systems and Automation (LMS), Greece

*E-mail: mourtzis@1ms.mech.upatras.gr https://doi.org/10.36897/jme/147160
} 
Artificial Intelligence (AI), and Big Data Analytics. Despite the significant trend toward automation, manual labour remains an economically viable option in some situations, particularly where there is a high level of complexity and variety in production. Many products and especially the complex ones, require hand-assembled steps. Although the proportion of monotonous and repetitive tasks will most likely continue to decline because of automation, it is expected that complex manual assembly will still require human skill sets in Industry 4.0 and beyond. A variety of technologies can be efficiently utilized to assist shopfloor technicians in the completion of their tasks without replacing them. Since the second half of the twentieth century, industrial robotics has accelerated manufacturing automation. The Fourth Industrial Revolution or Industry 4.0 (I4.0), has taken automation to the next level. Human labour will undergo significant changes in this context, but complex assembly will continue to require human skills. As such, until now the concept of Operator 4.0, which is defined as a technician who is assisted in performing his or her tasks by a number of technologies, is investigated in literature. Furthermore, support can be provided to help operators and technicians with both the physical and cognitive aspects of their jobs, according to Romero et al. (2016) [6]. Collaborative robots, Augmented Reality (AR), exoskeletons, and biometric tracking systems are just a few examples of these technologies. As a result, the Operator 4.0 concept was born $[7,8]$ and is defined as "A smart and skilled operator who performs not only cooperative work with robots but also work aided by machines as and when needed by means of human cyber-physical systems (...)". According to [9], implementing these technologies to assist humans in manufacturing is a major competitive advantage, but it also comes with a few challenges, including investment costs, compatibility, physical and mental workload, safety, and acceptability. Additionally, as per the World Economic Forum - Future of Jobs Report 2020 [10], there will be more talent available to fill jobs in technology and the green economy. These new jobs are expected to be at the cutting edge of the data and AI economy, engineering, cloud computing, and product development, implying an increase in upskilling requirements and related learning subjects. Based on the abovementioned challenges, this paper aims to meet the demand for modern education and training systems towards the next Industrial Revolution (Industry 5.0) the that equip job seekers with digital skills in order to close the digital skills gap and to to investigate the key technologies that will be the drivers towards the realization of the new generation of Operators (Operator 5.0) and to highlight the key challenges. In addition, the contribution is extended to a conceptual framework for training and support of the shopfloor technicians/operators based on the use of Extended Reality (XR), which incorporates Augmented Reality (AR), Mixed Reality (MR), and Virtual Reality (VR) for manufacturing processes such as machining operations and human-robot collaboration for assembly tasks.

The remainder of the paper is structured as follows. In Section 2 the evolution of Industry, Machine tool, Process Monitoring and the Operator (R)evolution are presented. Next, the Operator 4.0 typology is discussed based on the literature review as well as the social factory and the social operator concepts as well. Moving on, in Section 3 the concept of Resilient Operator and the key technologies are presented. Next, the Human Cyber Physical Systems model is introduced and finally in Section 5 the Industry 5.0 and a conceptual framework for collaborative work between the Operator 5.0 and Robots is discussed. The paper is summarized with Conclusions and Outlook in Section 6. 


\section{LITERATURE REVIEW}

\subsection{INDUSTRIAL REVOLUTIONS}

During the Fourth Industrial Revolution (also known as Industry 4.0) the concept of Cyber Physical Systems (CPS) [11, 12] has been transformed to Cyber Physical Production Systems (CPPS) [13]. The term Industry 4.0 is based on the definitions of the first three Industrial Revolutions as presented in Fig. 1. Production systems, in the form of Cyber Physical Production Systems (CPPS), can facilitate engineers into making intelligent decisions in the Industry 4.0 era, as a result of the real-time communication and cooperation between "manufacturing things" [14] allowing for flexible production of high-quality personalized products at scale $[15,16]$.

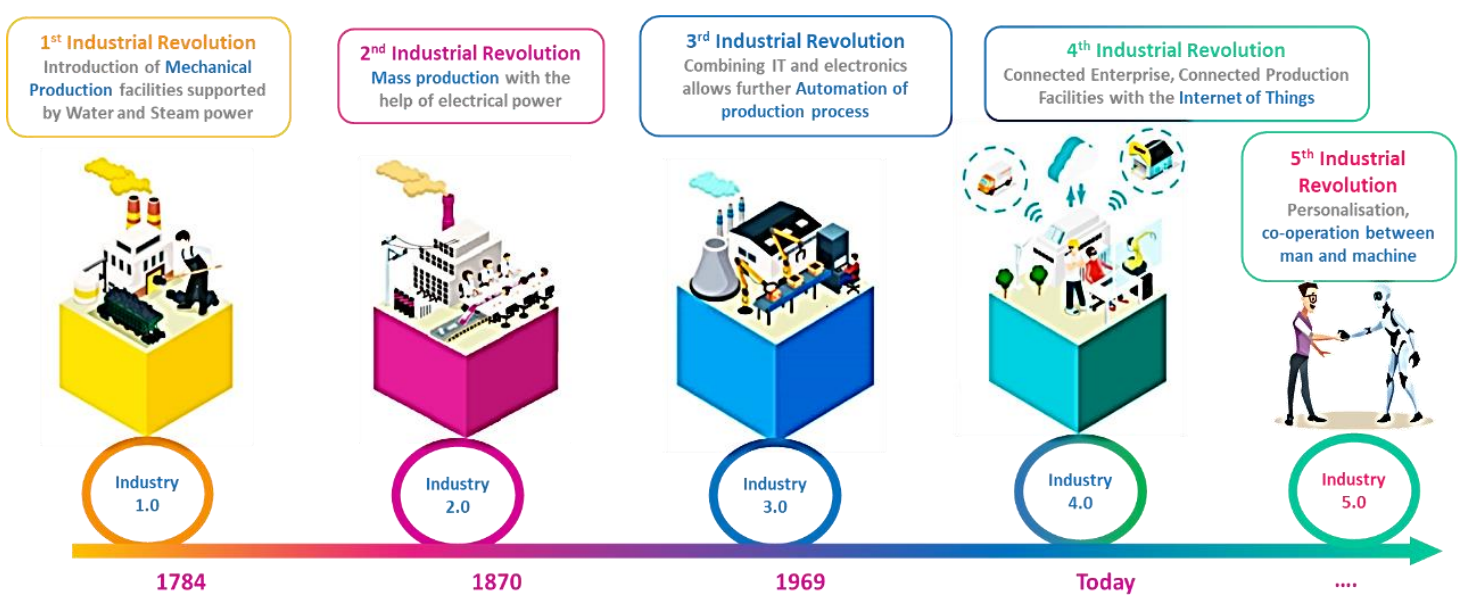

Fig. 1. The Five Industrial Revolutions (Adapted from [17])

The Fifth Industrial Revolution arrived as businesses began to embrace Industry 4.0. (Industry 5.0). Industry 5.0 is understood to recognize the power of industry to achieve societal goals beyond jobs and growth, to become a resilient provider of prosperity, by ensuring that production respects our planet's boundaries and places the well-being of industry technicians at the center of the manufacturing process [18, 19]. Industry 5.0 is based on the observation or assumption that Industry 4.0 focuses less on the original principles of social justice and sustainability and more on digitalization and AI-driven technologies for increasing production efficiency and flexibility. Consequently, the concept of Industry 5.0 offers a unique perspective and emphasizes the importance of research and innovation in assisting the industry in providing long-term service to humanity within planetary boundaries [20]. Furthermore, there have been some discussions about the "Age of Augmentation", during which humans and machines reconcile and work in symbiosis, leading up to the formal introduction of Industry 5.0 [21]. The growing integration of AI creates many challenges and opportunities for future workplaces. Even though Industry 4.0 has not been implemented worldwide, many industry innovators and technology leaders are looking forward to Industry 5.0 which will be characterized by autonomous manufacturing with human intelligence in and 
on the loop. To that end, Industry 5.0 combines the two main pillars of Industry 4.0 regarding automation and efficiency, as well as a personal human touch. Co-workers are people who work alongside robots, smart machines, and other key enabling technologies [17].

\subsection{MACHINE TOOL REVOLUTION}

The evolution of industrialization had significant impact on the evolution of machine tools. In Fig. 2, likewise the timeline of the industrial revolutions (Industry 1.0 to Industry 5.0), the Machine Tools Revolution is depicted.

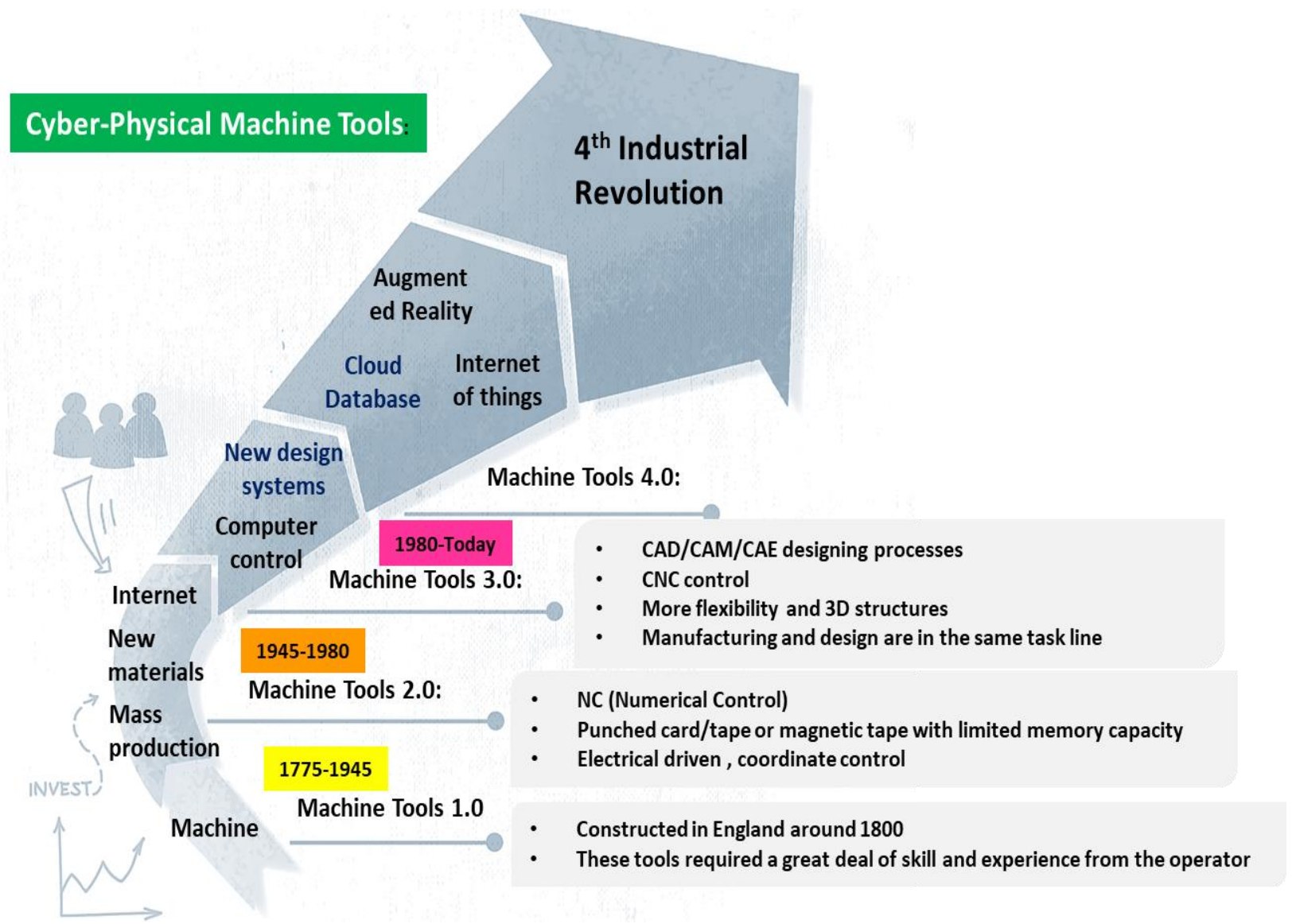

Fig. 2. Machine Tools Evolution (Adapted from [22])

Similarly, the evolution of machine tools can be divided into four stages [23]:

- Machine Tool 1.0: mechanically driven but manually operated, late 18th century.

- Machine Tool 2.0: electronically driven and numerically controlled, mid-20th century.

- Machine Tool 3.0: computer numerically controlled, late 20th century.

- Machine Tool 4.0/Cyber Physical Machine Tool 4.0: computer numerically controlled. 


\subsection{MACHINE PROCESS MONITORING EVOLUTION}

The trend toward smart sensors in the field of sensors and instrumentation has long been established in aspects such as better performance, higher integration, and multi-parameter sensing, as well as built-in intelligence and secure and safe networking. Intelligent sensor systems enable self-identification, diagnosis, calibration, and repair, and are often referred to as self-X. In a similar vein to Industry 4.0, Peter Krause, chairman of the AMA e.V. (AMA, 2018), coined the term Sensor 4.0 to describe the current state of sensors and measurement science. The evolution toward Smart Sensors or Sensors 4.0 depicted in Fig. 3 [24] also demonstrates how closely sensors and instrumentation are linked to industrial evolution.

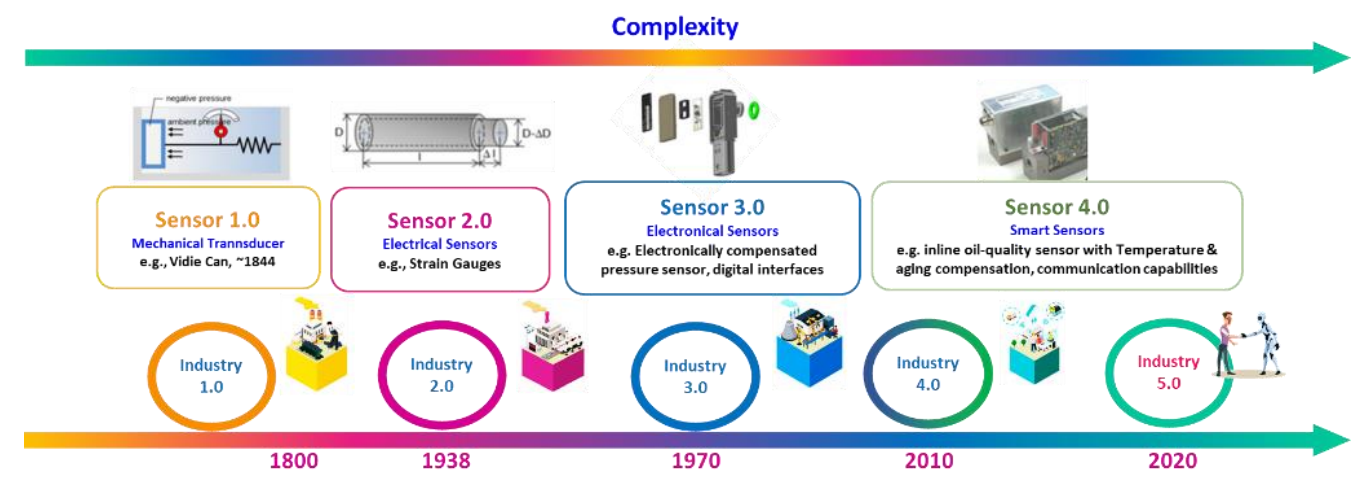

Fig. 3. Historic evolution from "Sensor 1.0" (without electrical output this is not a sensor according to the usual definition) to smart sensors, i.e. "Sensor 4.0" (Adapted from [24])

It is worth mentioning that sensors are not just important in industrial processes, but they are also influencing current megatrends like smart cities and smart mobility. Smartphones, for example, are the best examples of highly integrated sensor platforms because they typically integrate more than ten different sensors and heavily rely on multisensory signal evaluation, such as for navigation, which uses accelerometers, gyroscopes, magnetometers, and pressure sensors. These sensors are also used for other functions such as weather monitoring, screen orientation, step counting, and, finally, gaming. In this case, the sensors are considered "dumb", with data fusion and integration between different sensors resulting in a smart platform.

\subsection{OPERATOR GENERATIONS (R)EVOLUTION}

In order to accommodate the ever-increasing variability of production, Industry 4.0 enables new types of interactions between operators and machines, interactions that will transform the industrial workforce and have significant implications for the nature of work. The emphasis on human-centricity of the Factories of the Future is an important part of this transformation, allowing for a paradigm shift from independent automated and human 
activities to a human-automation symbiosis (or "human cyber-physical systems") [25] characterised by the cooperation of machines with humans in work systems and designed not to replace, but rather to co-exist with and assist humans in becoming more efficient.

The history of operators' interactions with various industrial and digital production technologies can thus be summarized as a generational evolution as presented in Fig. 4. As a result, the Operator 1.0 generation is defined as humans performing 'manual and dextrous work' with some mechanical and manually operated machine tool assistance. The Operator 2.0 generation is a human who performs 'assisted work' with the help of computer tools such as CAx tools, NC operating systems (such as CNC machine tools), and enterprise information systems. The Operator 3.0 generation represents a human being engaged in 'collaborative work' with robots, other machines, and computer tools, also known as human-robot collaboration. The Operator 4.0 generation represents the 'operator of Industry 4.0', a smart and skilled operator who, when and as needed, performs 'work aided' by machines. It represents a new design and engineering philosophy for adaptive production systems, focusing on treating automation as a means of enhancing human physical, sensorial, and cognitive capabilities through the integration of human cyber-physical systems [6].

\section{Operator Generations Evolution}

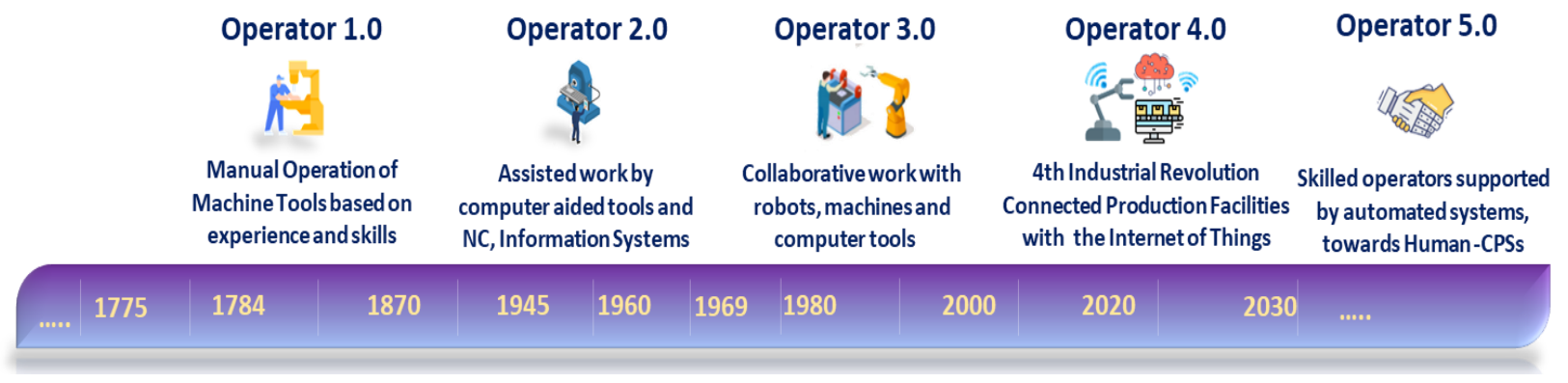

Fig. 4. Operator Generations (R)Evolution (Adapted from [26])

\subsection{THE ROLE OF OPERATOR IN FLEXIBLE MANUFACTURING SYSTEMS}

The operator in a Computer-Aided Manufacturing system (CAM) does not directly control the process of the system. Instead, the operator interacts with a computer, which then affects that control. As a result, the operator is becoming less concerned with manual control of the manufacturing system's inner loops and more concerned with supervisory control from the system's outer loops. In terms of the tasks carried out by CAM systems, the operator deals with information processing and decision-making, more than materials handling and manipulation [27]. Manufacturing processes have been transformed because of both the introduction of numerical control and the introduction of robotics (NC) to the so-called manufacturing paradigm of "Flexible Manufacturing Systems (FMS)" [28]. The FMS has several important manufacturing advantages, including the ability to produce families of work parts, reduced manufacturing lead times, increased machine utilization, and so on. FMSs also bring about unavoidable changes in the work content, focusing on operator supervisory and maintenance responsibilities [29]. The authors in [30] have discussed the overall role 
of operator in FMSs. The operator is thought to have three major roles in FMS, in particular (a) maintenance, part loading and unloading, (b) tool change and inspection, and (c) supervisory control of the entire FMS process.

Another issue with Human-Computer Interfaces (HCIs) in FMSs is to decide which tasks should be assigned to the computer and which should be assigned to the operator. The introduction of a factory management system has altered the nature of the tasks performed by operators in manufacturing systems. While the overall number of tasks has decreased, the amount of decision-making and data processing has increased. In some cases, the operator must match their information processing and decision-making speed to the speed at which computers present and process data. As a result, one of the most difficult problems for humanfactors experts is figuring out how to create jobs that are manageable for operators who must interact with the computers that control FMSs. Moving on to the era of automation, it can be mentioned that automation can refer to either open-loop or closed-loop environmental control. Human intervention can take several forms:

1) human in the loop (human intervention),

2) human out of the loop (controller intervention),

3) and human on the loop (human intervention) (supervisory control mode over the controlled process).

Basic automation replaces human manual control with an automatic controller; however, humans are still required for supervision, adjustment, maintenance, expansion, and improvement in highly automated systems. Additionally, the level of complexity is increased with automation. The complexity of industrial human process supervision necessitates a cross-disciplinary approach to integrate knowledge and methods from other fields, particularly Automation and AI. As such, the need to deal with larger amounts of data and the ability to interact with other subsystems of the production chain necessitates the use of appropriate modelling methods and simulation tools. Furthermore, integration of supervision (Supervisory Control And Data Acquisition - SCADA software), management (Manufac-turing Execution Systems - MES; and Enterprise Resource Planning - ERP) and production planning tools is another step that was considered towards the shift from Operator 3.0 to Operator 4.0. To that end, the authors in [31] presented a study program on automated production management that integrates MES and ERP systems at the top of the Computer Integrated Manufacturing CIM pyramid. More specifically, at the top level are the humancomputer interaction and human supervisory task, whereas at the bottom level are humancomputer interaction and human supervisory task. At such FMS system, the monitoring interface is linked to the actions of a human operator near to an industrial machine (automation level). Therefore, a critical skill is the ability to understand the knowledge of the behavior of the devices.

Moving on from FMS to Automatically Adapted Workplaces (AAK), or the first Industry 4.0 line on-stream in daily production, a characteristic example is the Rexroth Plant, Homburg (A Bosch Company). At this AAK, individual workplaces adapt to the needs of their operators automatically. This is accomplished using Bluetooth tags with a user profile, which are worn by each employee and read by the assembly station. As a result, the station's lighting or the font size and language on the monitor can be adjusted accordingly. Even the depth of information on the monitor screen adjusts automatically based on the user's 
qualifications. Thus, Bosch Rexroth received the "Industrie 4.0 Award" from the trade magazine "Produktion" for the best networking of humans, machines, and processes [32].

\subsection{OPERATOR 4.0 TYPOLOGY}

From a social manufacturing perspective, the so-called Operator 4.0 typology depicts how Industry 4.0 technologies can help operators become "smarter operators" in their future factory workplaces. It has to be mentioned that Operators 4.0 can be found on the shop floor in single- or hybrid-type configurations. Below is a list of various enhancements to the original human capabilities even though the Operator 4.0 may include a variety of other features. These enhancements are available in a variety of levels and can also be combined. It is also possible that the Operator 4.0 will only be improved in one area while the other aspects are ignored. In some cases, this will be impossible (for example, augmented reality functionality requires a 'connected operator' to function). As per Romero et al. (2016) [6] the following enhancements can be applied to the current Operator 4.0:

- Operator + Exoskeleton $=$ Super-Strength Operator [physical interaction] [33]

- Operator + Augmented Reality = Augmented Operator [cognitive interaction] [34].

- Operator + Virtual Reality = Virtual Operator [cognitive interaction] [35].

- Operator + Wearable Tracker = Healthy Operator [physical and cognitive interaction].

- Operator + IntelligentPersonalAssistant=Smarter Operator[cognitiveinteraction] [36].

- Operator + Collaborative Robot $=$ Collaborative Operator [physical interaction] [37] .

- Operator + Social Networks = Social Operator [cognitive interaction [38]

- Operator + Big Data Analytics = Analytical Operator [cognitive interaction] [39].

In order to integrate and fill the technologies used by/connected to the Operator 4.0 with human values, it is necessary to clearly define the boundaries. As a result, the authors in [40] introduce the Operator 4.0 Compass, a tool created with the ultimate goal of providing a clear description of the meaning of Operator 4.0 in relation to the full and comprehensive set of technologies related to industrial technicians' activities and capabilities.

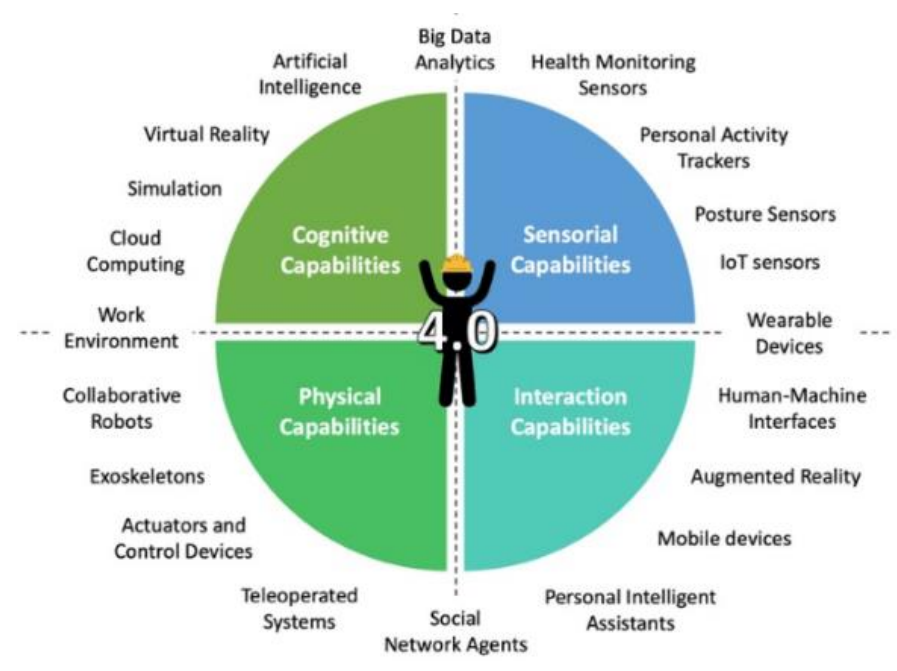

Fig. 5. Operator 4.0 Compass [40] 
The Operator 4.0 is defined as "an industrial technician whose cognitive, sensorial, physical, and interaction capabilities are enhanced by the close interaction with Industry 4.0 technologies", according to this tool (see Fig. 5). While the Boston Consulting Group identifies nine Industry 4.0 key enabling technologies, a thorough examination of how the capabilities of industrial technicians can be improved led to the consideration of twenty Operator 4.0 key enabling technologies, which have been classified according to the specific capability they (primarily) enhance. As a result, the following classification is used:

- Technologies enhancing the operator's cognitive capabilities

○ Cloud Computing

- Simulation

O VR

○ AI

- Technologies enhancing the operator's sensorial capabilities

- Health Monitoring Sensors

○ Personal Activity Trackers

○ Posture Sensors

○ IoT Sensors

- Technologies enhancing the operator's physical capabilities

o Collaborative Robots

- Exoskeletons

- Actuators and Control Devices

- Teleoperated Systems

- Technologies enhancing the operator's interaction capabilities

o Human-Machine Interfaces (HMI)

○ AR

○ Mobile Devices

o Personal Intelligent Assistants.

Finally, the following four technologies/parameters can be located in between two or more of the abovementioned groups:

- Big Data Analytics (technologies enhancing the operator's cognitive and sensorial capabilities).

- Wearable Devices (technologies enhancing the operator's sensorial and interaction capabilities.

- Work Environment (technologies enhancing the operator's cognitive and physical capabilities).

- Social Network Agents (technologies enhancing the operator's physical and interaction capabilities).

\subsection{THE SOCIAL OPERATOR 4.0}

The Operator 4.0 can be defined as a smart and skilled operator who performs not only "cooperative work" with robots, but also "work aided" by machines as and when needed, using human cyber-physical systems, advanced HMI technologies, and adaptive automation 
towards "human-automation symbiosis work systems". Furthermore, a Social Operator 4.0 is a type of Operator 4.0 that uses smart wearable solutions and advanced HMI technologies to collaborate with other social operators, social machines, and social software systems to communicate and exchange information for mutual benefit, align/alter activities, and share resources in order to achieve more efficient results at the smart and social factory of Industry $4.0[6]$.

When combining different interaction mechanisms, sharing and trading control strategies between social operators, social machines, and social software systems towards a social factory [7], smart wearable solutions [41], HMI technologies [42], and adaptive automation strategies [43] will play a significant role when combining different interaction mechanisms and sharing and trading control strategies between social operators, social machines, and social software systems.

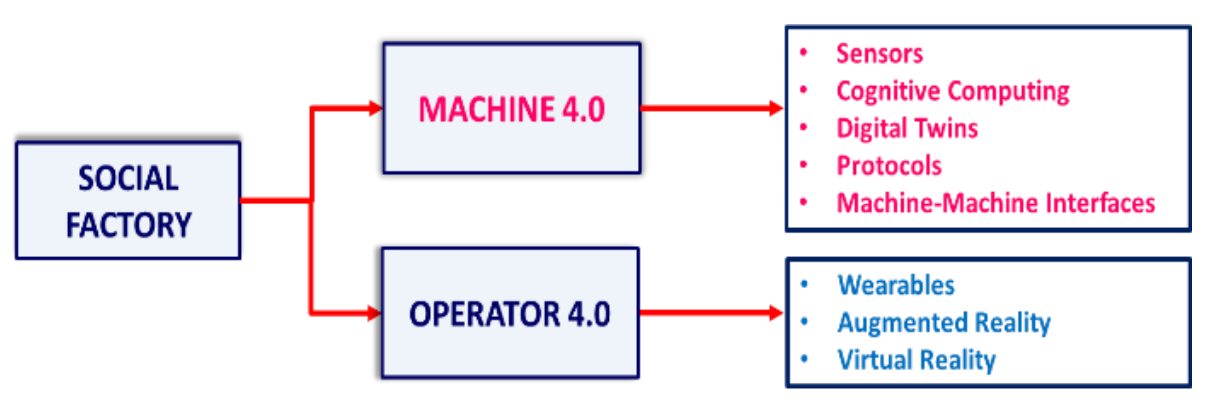

Fig. 6. The Key Components of the Social Factory

A Social Factory is a real-time enterprise social network with a powerful middleware and analytics backend to improve the connection between social operators, social machines, and social software systems working together in a smart manufacturing environment, as well as the data generated during the networking process. A social factory, should be able to (see Fig. 6):

- Provide the right information to the right person, machine, and/or software at the right time and place (anywhere and anytime).

- Support humans under any working conditions.

- Engage humans to contribute to new knowledge creation.

- Treat humans, machines, and software as equal partners.

- Learn from all this socialization of knowledge by explicitly expressing it. [44].

\subsection{HUMAN CAPITAL / OPERATOR IN INDUSTRY 4.0}

Knowledge and education are two of the most important human capital possibilities, as they help the Fourth Industrial Revolution achieve the desired goals, which benefit institutions. According to the human capital theory, knowledge provides individuals with greater cognitive skills, so it is necessary to boost their productivity and efficiency in order to develop related activities. Therefore, employees in the smart and social factories must have 
a certain level of education, experience, knowledge, and skillset, which are used to create added value towards the success of an organization. As a result, it becomes evident how experience, knowledge, skills, and education are important for human capital in organizations, emphasizing the importance and role of human capital within the Industrial Landscape. Thus, smart manufacturing requires not only a workforce, but also human capital, which must be well prepared for creative work environments and nurtured in competitive education systems [45]. Therefore, it has become critical for countries and organizations to develop suitable education systems that are more focused on knowledge that goes beyond what the world currently addresses. This necessitates creative personalized teaching, extending to the highest education level (i.e. university level) [46]. Due to the fact that the current educational systems do not produce thinkers, creators, or ingenuity, a new shift away from traditional education systems of writing, reading, and memorization is required. As a result, countries have to transform their educational systems in order to produce super-operators capable of implementing the complexity imposed of the several digital technologies of Industry 4.0 and beyond.

\subsection{SOCIAL FACTORY ARCHITECTURE}

The Next Generation Balanced Automated Production Systems (NGBAPS) are made up of "hardware" (such as machine tools and robots), software (such as enterprise information systems), and human ware (such as blue-collar and white-collar technicians) components that coexist with mechanical and human autonomy, as well as human-machine collaboration capabilities, to create a socially sustainable and competitive factory. Several smart wearable solutions, which are part of the Social Internet of Industrial Things (SIoIT) paradigm, have been designed for a variety of purposes and for wear on a variety of body parts, such as the head, eyes, wrist, waist, hands, fingers, and legs, or embedded into various elements of attire [47], in order to tech-augment operators' physical, sensorial, and cognitive capabilities [48]. The goal of Agent Technology (AT) is to bridge the gap between humans and technological devices. As a result, AT has been regarded as an important approach for developing socially sustainable factories, where human agents can collaborate (socialize) with other human agents and artificial (machine) agents as hybrid agents and emerging agents to maintain their agenthood, and thus optimally leverage human skills and automation capabilities on the shop floor in order to provide human inclusivity and harness the strengths of humans and machines to achieve new levels of productivity [48].

To achieve human-automation symbiosis [49] at the social factory and its smart production environment, it is proposed to use an intelligent and actively adaptive collaborative multi-agent system to coordinate the support of manufacturing and services operations at the shopfloor. Active interfaces within the factory's social IoTSP (Internet of Things, Services and People), acting as interface agents, will be able to gather information about the agenthood status of social operators, social machines, and social software systems, and send a request for cooperation (i.e., to create a hybrid or emergent agent) to other human or artificial (machine) agents in order to keep their agenthood, and thus production, running. As such, the social factory should be viewed as a "collaborative environment of intelligent 
multi-agents" [50], in which (real) humans and machines "twin agents" use interface agents to facilitate communication between them and the cyber and physical worlds, and other agents such as broker agents support task allocation, control sharing, and trading [51] in the cyberphysical production environment. Fig. 7 depicts a high-level Social Factory Architecture based on a Multi-Agent System that is Adaptive, Collaborative, and Intelligent (ACI-MAS).

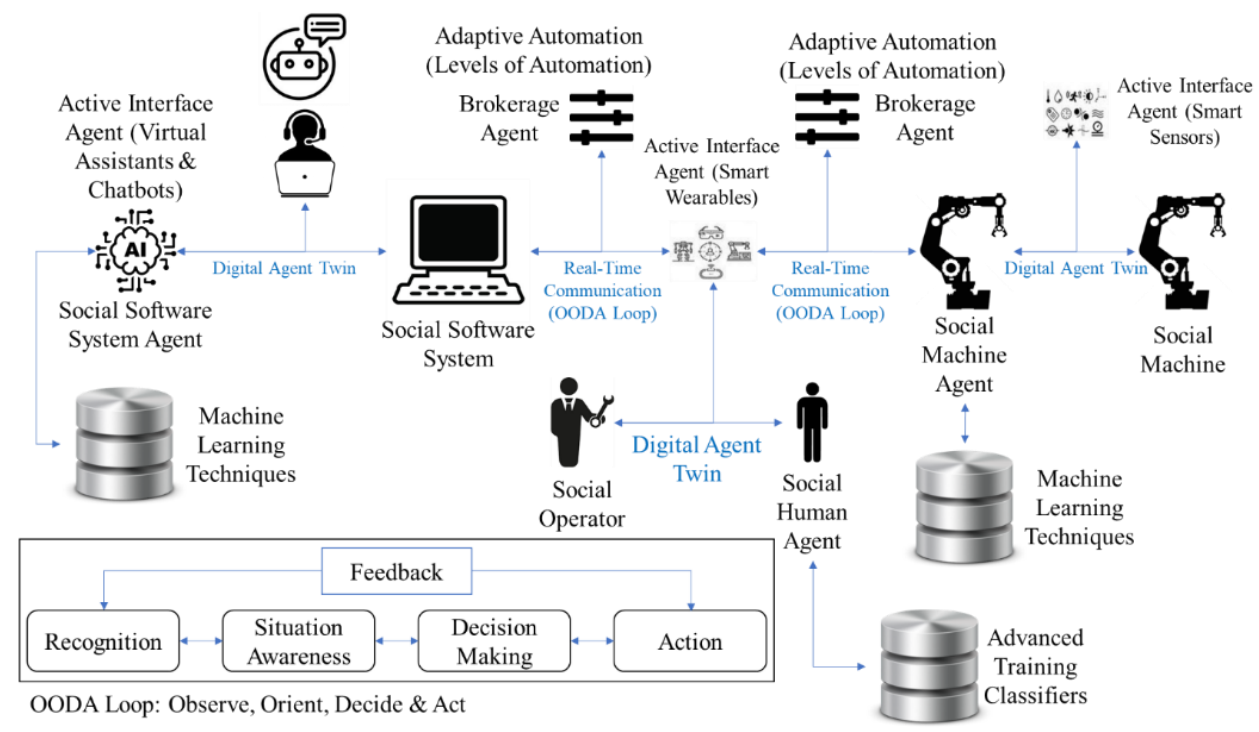

Fig. 7. High-level social factory architecture based on an ACI-MAS [8]

\subsection{DEVELOPMENT OF SHOP FLOOR SKILLS FOR SMART AND SOCIAL FACTORY}

From a sociological point of view, the qualification of the industrial workforce is a core issue of Industry 4.0. Industrial sociology, in conjunction with vocational training research, attempts to assess the smart factory's qualification requirements. In literature, on the shop floors of the smart factory, the vision of realizing expanded decision-making and participation scope, as well as possibilities for working load regulation, is questioned. At least according to sociological researchers, there is no clear path to more self-responsible autonomy and greater decision-making power for workshop operators. Furthermore, certain precautions must be taken to ensure that shop-floor workers are fit for work in the smart factory and that the highest possible level of "decent work" is maintained. In-company qualification or additional training measures are the most suitable means of implementing and securing the abovementioned challenges. Additionally, the following are possible competencies for electronics technicians working in "system integration" for automation technology [52]:

- Analyzing functional relationships and process flows in the Industry 4.0 era.

- As part of the Reference Architecture Model Industrie (RAMI) 4.0 Layer, install, configure, and parameterize the Industry 4.0 components, systems, and networks.

- Connecting components to complex automation devices and integrating them into the Industry 4.0 layers functional layers.

- Industry 4.0 systems are monitored, tested, maintained, and repaired. 
Additionally, it is also becoming increasingly important that production business model has to be able to operate under a variety of qualification conditions around the world under a wide variety of disruptions, and thus obtain a resilient. As a result, either the technology or the workforce's qualifications must be more adaptive [53]. It is also crucial to think about the effects of global networking structures linked to "Industry 4.0" on skill development. As a result, globalized networks may become a limiting factor to workers' autonomy and selfdirection [54].

\section{TOWARDS THE RESILIENT OPERATOR 5.0}

\subsection{TOWARDS THE RESILIENT OPERATOR 5.0}

A Resilient Manufacturing System is defined as "a system with the ability to adjust its functioning prior to, during, or after operational changes and disturbances, so that it can sustain required operations under both expected and unexpected conditions" $[55,56]$. The extent to which manufacturing activities are able to withstand and/or quickly recover from operational disruptions that pose a threat to the continued operation of manufacturing operations at the desired level demonstrates this resilience [57]. Smart and resilient human operators must adjust what they do and how they do it, as well as what machines do and how they do it, in both "ilities" of a sustainable manufacturing system, to match current demands and available resources to the realities of the business operations at the time. As a result, in all situations involving change, human operators are required. Thus, as the Industry 4.0 paradigm develops smart and resilient capabilities in next-generation manufacturing systems, it should also be developing smart and resilient capabilities in the workforce that will operate them. Based on the abovementioned, the concept of Operator 5.0 has been introduced in literature $[6,58]$. More specifically, the "Resilient Operator 5.0" is defined as a smart and skilled operator who uses human creativity, ingenuity, and innovation, aided by information and technology, to overcome obstacles on the way to developing new, cost-effective solutions for ensuring manufacturing operations' long-term sustainability and workforce well-being in the face of difficult and/or unexpected conditions [59]. As such, a Smart Resilient Manufacturing System can be defined as an agile and flexible/reconfigurable system that collects and analyzes operational and environmental data in real time using smart sensor systems and descriptive, predictive, and prescriptive analytics techniques in order to predict, react, and recover from a disruption.

However, depending on the sophistication of the manufacturing system's capabilities, the level of automation in the reaction may vary, necessitating human participation in the majority of circumstances when change is necessary [60]. As a result, a manufacturing system's degree of resilience will be determined by one side of the resilience of its weakest sub-system. Due to its (human) frailty, this will often be the human system. On the other hand, it will rely on its most powerful sub-system, which may also be the human system, due to its intuitive skills to avoid negative outcomes or perform better than predicted when faced with new obstacles. Therefore, it can be argued that in order to engineer a true Smart Resilient Manufacturing System, the proper balance between manufacturing activities' automation and 
mechanization [49] as well as human and AI, will be required to develop manufacturing intelligence [61] and adopt resilience heuristics [62] such as human-in-the-loop, when rapid cognition and creative option generation are required, and human backup, when (human) operators should rely on their own judgment.

The Resilient Operator 5.0 vision is two-fold: on the one hand, it focuses on creating "self-resilience" for the workforce due to its natural (human) fragility, and on the other hand, it focuses on "system-resilience" for all human-machine systems in a manufacturing system where human operators and machines collaborate to ensure the overall system's optimal operation.

- Self-resilience is concerned with each shop floor operator's biological, physical, cognitive, and psychological occupational health and safety, as well as productivity.

- System-resilience considers alternative ways for human-machine systems to continue operating, such as sharing and trading control between humans and machines to ensure system operational continuity [51].

The Fifth Industrial Revolution or Industry 5.0 will bring human technicians back to factory floors, combining human and machine brainpower and creativity to increase process efficiency by combining workflows with intelligent systems. While automation is the main concern in Industry 4.0, Industry 5.0 will be a collaboration between humans and autonomous machines. Human intention and desire will be perceptible and informed by the autonomous workforce. Humans will work alongside robots without fear, and with peace of mind, knowing that their robotic co-workers fully comprehend them and are capable of effectively collaborating with them. It will result in a highly efficient and value-added manufacturing process, thriving trusted autonomy, and reduced waste and costs. The definition of "robot" will change as a result of Industry 5.0. Robots will not only be programmable machines capable of performing repetitive tasks, but they will also be able to transform into the ideal human companion in certain situations.

The next industrial revolution will introduce the next generation of robots, commonly referred to as cobots, that will already know or quickly learn what to do, providing robotic productions with a human touch. Because these collaborative robots will be aware of the presence of humans, they will ensure that safety and risk criteria are met. Not only can they notice, understand, and feel a human being, but they can also notice, understand, and feel the goals and expectations of a human operator. Cobots, like apprentices, will observe and learn how a person performs a task. Once they have learned, the cobots will carry out the tasks as if they were human operators. As a result, when humans work alongside cobots, they have a different sense of fulfillment.

A typical example of a collaborative task between the Human Operator 5.0 (see Fig. 8) and a robot can be described as follows [63]:

- A human technician begins a task.

- A robot uses a camera on a gimbal to observe the process.

- This camera serves as the eye of the robot.

- The robot is also connected to a processing computer that takes the image processes it, and uses Machine Learning (ML) to learn the pattern.

- It also uses human intention analysis powered by Deep Learning (DL) to observe the human, monitor the environment, and predict what the operator will do next. 
As a result, Industry 5.0 will result in the creation of a new manufacturing position: the so-called Chief Robotics Officer (CRO). A CRO is a person who is knowledgeable about robots and their interactions with humans. To achieve optimal performance and efficiency, the $\mathrm{CRO}$ will be in charge of making decisions about which machines or robots should be added or removed from the environment/factory floor. Robotics, AI, human factors modeling, and Human-Machine Interaction (HMI) will all be the key areas of expertise for CROs. The CROs are better equipped with collaborative robotic technologies and will be well-positioned to make a positive impact on environmental management by leveraging the power of advances in computation. This will eventually improve human civilization's long-term viability by reducing pollution and waste generation while also preserving the environment [63].

Additionally, the role distribution between a human operator and the machine control needs to be re-defined as a result of the argumentation in academia regarding the necessity of Industry 5.0. As such, biological properties must be replicated in the manufacturing system. Bio-inspiration is not a new concept, but instead of simply copying natural structures, it now entails the adoption of functional properties of biological systems, which allow the operator to be more relieved and thus have a greater degree of autonomy. After some preliminary work by Ueda [64] and Malshe et al. [65], Byrne et al. [66] launched the biological transformation in manufacturing. El Maraghy et al. [2] also presented a road map for the future development of manufacturing systems in their keynote paper. The following are some of the key characteristics that distinguish biological systems from technical systems [67]: a) Intelligence, b) Abundance of sensors, c) Information exchange, d) Health maintenance, and e) Functional Integration.

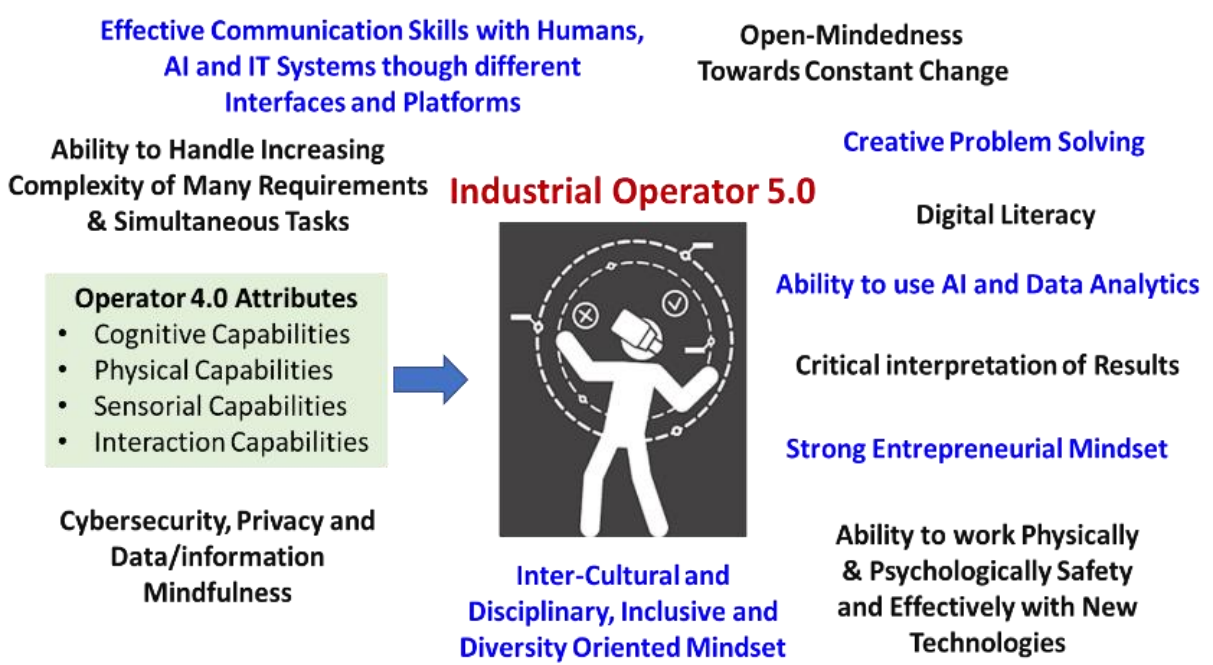

Fig. 8. Skills and Attributes of the Industrial Operator 5.0

\section{TOWARDS HUMAN CYBER-PHYSICAL SYSTEMS}

Human Cyber-Physical Systems (H-CPS) are the next step in the evolution of HMI and physical-digital worlds interfacing for the purpose of augmenting or improving human 
performance. H-CPS aim to become safety (fault tolerance) engineered systems of systems with the human-in-the-loop, using context-sensitive, advanced communication, and adaptive control technologies to support inter-agent systems of humans, machines, and software to interface in the virtual and physical worlds towards a sustainable and human-centric production system. H-CPS will be deployed on the shop floor to optimize the outcome of a production system while also considering the manufacturing's social sustainability.

In H-CPS for the new-generation intelligent manufacturing (NGIM), the role of humans as "master" is even more prominent [68]. Human abilities and skills will be greatly enhanced as creators, managers, and operators of intelligent machines, and their intellectual potential will be fully unleashed for further emancipation of the productive forces. Humans will be freed from a significant amount of intellectual and manual labour as a result of knowledge engineering, allowing them to focus on more valuable creative work. Intelligent manufacturing is a broad concept that has evolved over time as information technology and manufacturing technology have become more integrated. Due to the recent fast-paced development and influential breakthroughs in the internet, big data, and AI, intelligent manufacturing has progressed through the stages of digital manufacturing and digitalnetworked manufacturing and is now evolving toward new-generation intelligent manufacturing (NGIM) [16, 18].

Therefore, intelligent manufacturing will benefit human operators. Intelligent manufacturing is evolving from Human Production Systems (HPS) to HCPS1.0, then from HCPS1.0 to HCPS1.5, and will advance stage by stage as illustrated in Fig. 9 [69].

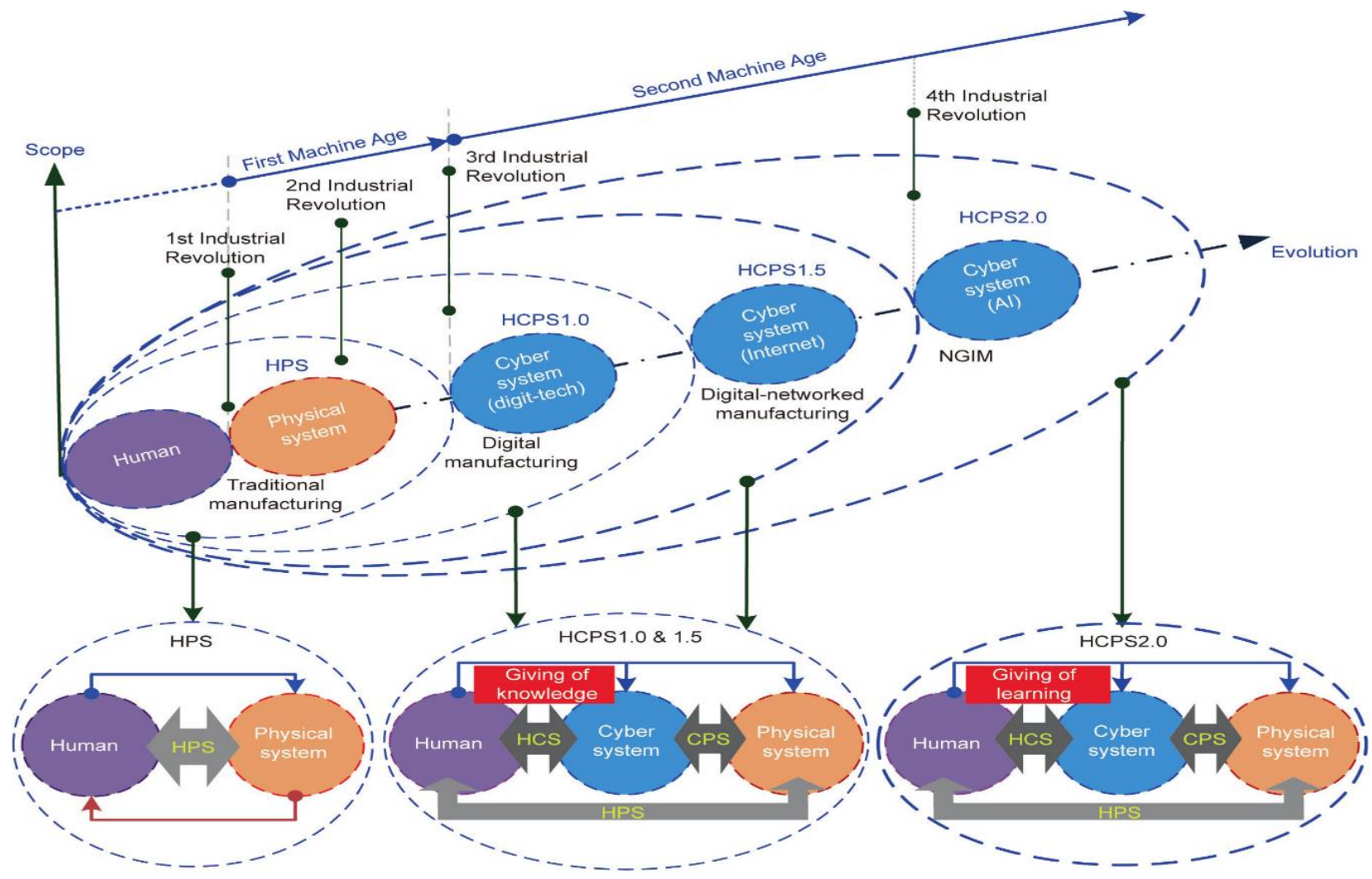

Fig. 9. Evolution of HCPS-based intelligent manufacturing [69] 
Moving on, Human-Machine Collaboration (HMC) has resulted in numerous changes in production, as well as economic and environmental consequences. Due to intense competition, manufacturers are under pressure to cut costs, which can be accomplished through zero-waste production. Zero-waste production promotes a healthy ecosystem while also focusing on the human side of manufacturing. Consequently, taking into consideration the societal impacts of industry 4.0, it is time to advance from Industry 4.0 to Industry 5.0, during which robots and human intelligence will supplement CPS. Almost all industries will work on the IoT era, which will be based on Big Data sets generated by these IoT devices. Additionally, the primary goal of Industry 5.0 is to create an evolutionary and incremental advancement of Industry 4.0. Collaborative robots, also known as cobots, are a concept introduced in Industry 5.0. These collaborative robots are the tools needed to meet the needs of today's businesses that produce personalized products for their customers. Human intelligence is applied by collaborative robots. People, AI, and the physical systems of businesses are all connected through high-speed internet in the HCPS. The fifth revolution focuses on integrating software and hardware technologies, as well as introducing intelligent resources for automating usage operations. HCPS is now capable of improving learning and applying it to generate knowledge using advanced sensing, computation, and control capabilities. Fig. 10 depicts a typical Human Intelligent based CPS structure. Big data is used as an input by the Intelligent Cyber Physical System for learning and knowledge generation and it was also enhanced by expert knowledge. Finally, expert knowledge and AI are combined to make decisions for a specific problem in the cyber-physical system as a whole. The Fig. 10 depicts knowledge flow mechanisms and how to construct a workable physical system that includes a computable and executable solution for transforming data, information, and knowledge into intelligence.

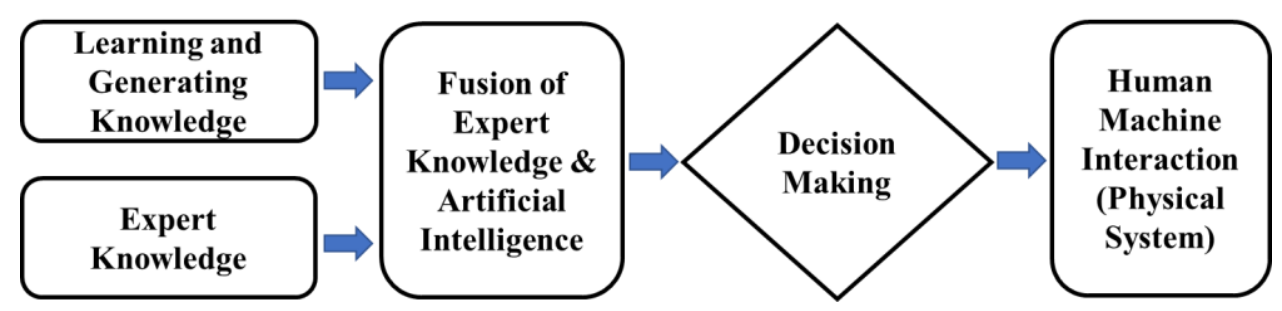

Fig. 10. Intelligent and Human based Cyber Physical System [70]

\section{DEFINING INDUSTRY 5.0 AND PROPOSED FRAMEWORK}

\subsection{INDUSTRY 5.0}

Since the European Commission released its Policy Brief on "Industry 5.0 - Towards a Sustainable, Human-Centric, and Resilient European Industry" [17], several reactions and discussions have been observed in the research community. Industry 4.0 is more technologyfocused, whereas Industry 5.0 is more value-driven toward practical implementations 
of available enabling technologies in industry [71]. As shown in Fig. 11, the core values of Industry 5.0 are supported by three interconnected pillars: 1) human centricity, 2) sustainability, and 3) resilience.

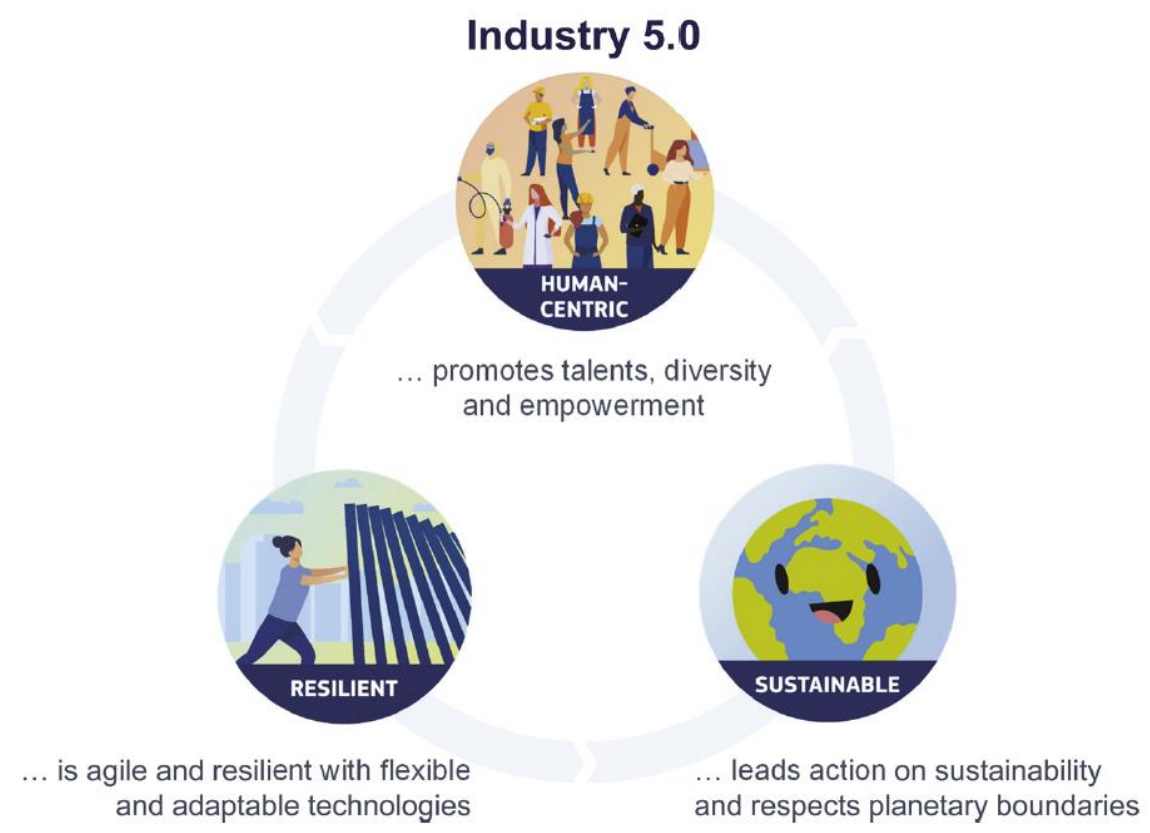

Fig. 11. Three pillars supporting the core values of Industry 5.0 [71]

The main takeaway from the discussions is that Industry 5.0 is more than just a chronological continuation of Industry 4.0. More specifically, it complements and extends its key features. What should be carefully considered and seriously is how to apply Industry 4.0 enabled technologies in future factories while preserving and maximising the core values of Industry 5.0. The author in [72] aim to share his perspective on future smart manufacturing from the perspective of human-centricity, with a focus on component assembly. Additionally, a futuristic perspective facilitated by four enhanced human abilities (EHAs) by augmented robot, cognitive system, MR, and co-intelligence in order to energise, advise, support, and empower (EASE) a human operator intellectually and physically is discussed. As previously stated, Industry 5.0 will address the issues associated with the removal of human technicians from various processes. However, this will necessitate even more advanced technologies, which will be presented hereinafter [63]:

- Networked Sensor Data Interoperability [73].

- Multiscale Dynamic Modelling and Simulation: Digital Twins [74, 75].

- Shopfloor Trackers [76].

- Virtual Training [77].

- Intelligent Autonomous Systems [78].

- Advances in Sensing Technologies and Machine Cognition [79].

The replication of the human senses, that we use to cooperate with others and learn in an adaptive manner will be critical for intelligent autonomous systems [80]. Combining computer vision [81] with DL [82], reinforcement learning [83], and GPU-based computation 
[84] has shown great promise in replicating primitive vision and sensory abilities. These capabilities, however, must be significantly enhanced for Industry 5.0 cobots. A human technician, for example, will stop working if he or she suspects something unnatural in his or her workplace, even if there is nothing wrong on the surface, because they have emotional intelligence. Preventing workplace accidents requires this type of anticipatory behaviour. The current vision and cognition technologies are incapable of achieving this. Machine cognition, in addition to vision and sensory technologies, must improve in order to make the best decisions in an ever-changing workplace environment. Developing a highly adaptive system can achieve this capability, but it is not simple to do so because no model, data, or rule-based system can do so on its own with our current technologies. In order to replicate what a human operator would normally do in a given scenario, other sensory technologies and their analyses must also be improved.

\subsection{FRAMEWORK FOR DIGITAL MANUFACTURING BASED ON EXTENDED REALITY}

The idea of using computer-mediated reality to improve human perception dates to the 1960s [85]. It has devolved into various subsets over time, resulting in a plethora of terminologies that can be confusing to many. In this research work, the term Extended Reality (XR) is used to refer to all computer-mediated reality technologies that combine the physical and virtual worlds to provide a more immersive experience. It is critical to understand the various types of XR systems so that the best decisions can be made for any specific manufacturing application [86]. The reality-virtuality continuum [87], in which the real-world environment and the virtual environment are on opposite ends, is a widely adopted approach. As shown in Fig. 12, augmented reality (AR), mixed reality (MR), and virtual reality (VR) emerge as the amount of virtuality increases from left to right (VR).

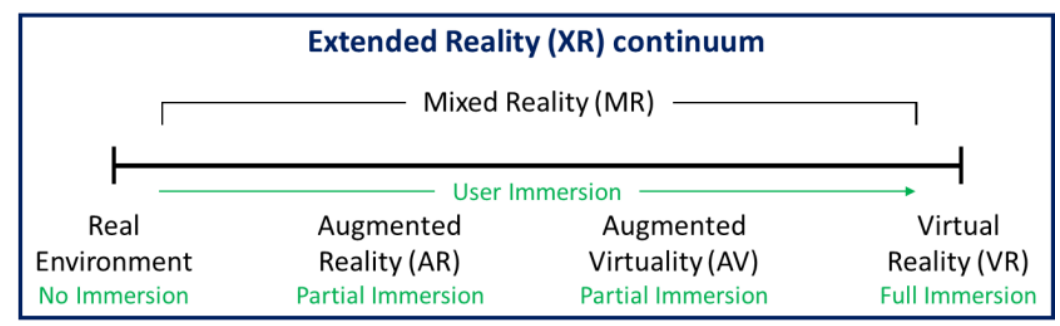

Fig. 12. The Reality-Virtuality Continuum based on the initial perception of Milgram [87]

\section{Augmented Reality - AR}

Azuma proposed the most widely accepted definition of AR in his survey paper [88]. According to Azuma, AR must have three characteristics: a) combines real and virtual, b) interactive in real time and c) registered in $3 \mathrm{D}$

\section{Mixed Reality - MR}

Mixed reality applications are defined as those in which "real world and virtual world objects are presented together within a single display, that is, anywhere between the virtuality 
continuum's extremes". The virtual objects are not only overlaid onto the real world, but users can also interact with them as if they were real objects, making MR systems one step beyond AR. A headset with an integrated computer, translucent glass, and sensor is required to achieve the MR experience. The real-world environment is typically mapped in real-time using integrated sensors, allowing virtual objects to interact with the real-world environment and users. MR is a more immersive and interactive version of AR. The Microsoft HoloLens [89] is a well-known MR headset that has been used in several reported MR applications.

Virtual Reality - VR

Virtual reality (VR) is defined as "the use of real-time digital computers and other special hardware and software to generate a simulation of an alternate world or environment that the users believe to be real or true".

In literature, a five-step framework of user-centered extended reality system development is analyzed in [90] (Fig. 13). It proposes a systematic process for XR system integration in the manufacturing context, with iterations of five serial steps, as presented hereafter, based on the success experience and lessons learned from empirical cases: a) Step One: Understanding Requirements, b) Step Two: Solution Selection, c) Step Three: Data Preparation, d) Step Four: System Implementation and e) Step Five: System Evaluation.

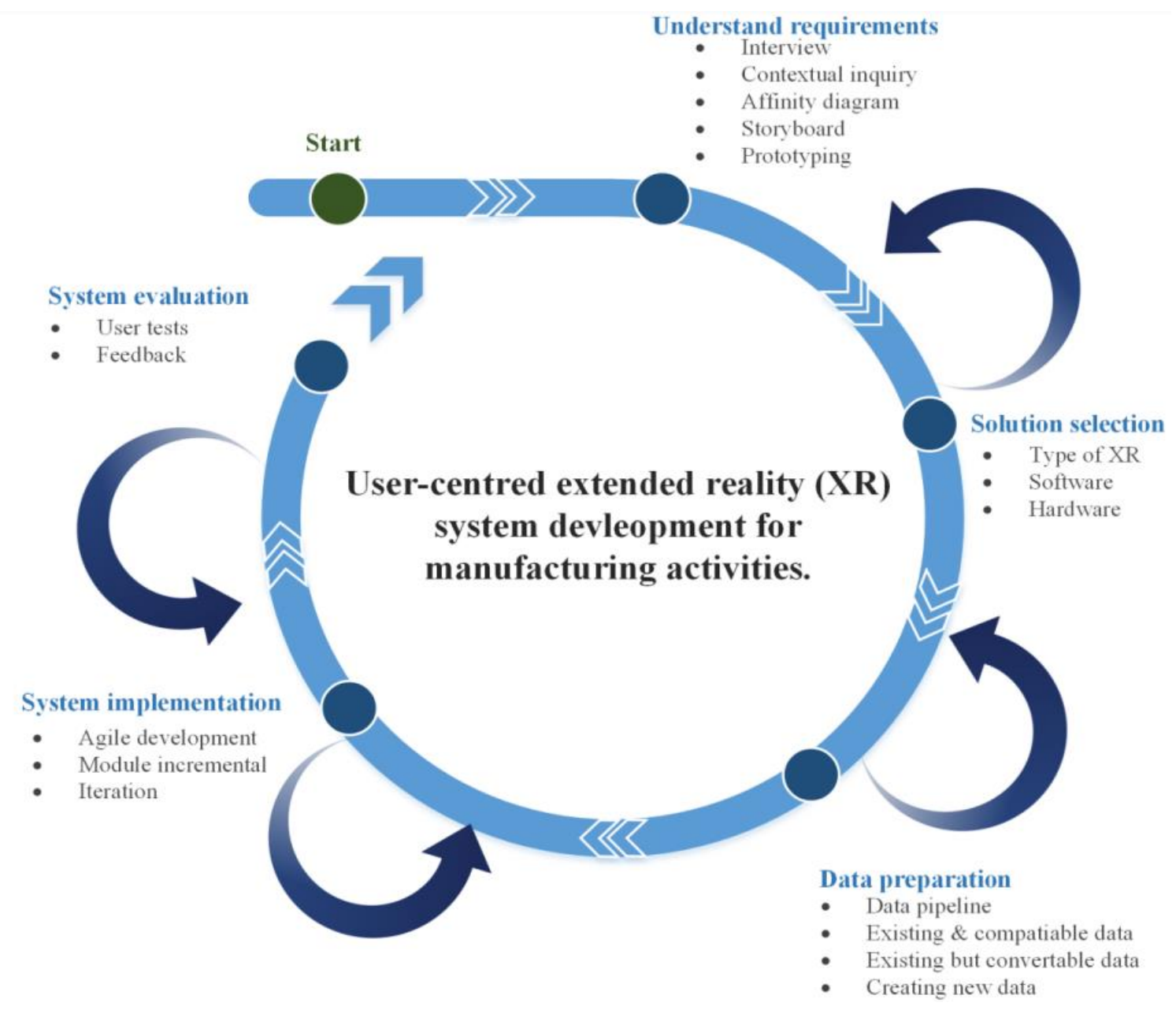

Fig. 13. The framework of user-centered extended reality system development for manufacturing activities [90] 
Based on the above-mentioned, a conceptual framework is presented in Fig. 14 to depict the collaborative framework of the Operator 5.0, using cutting edge digital technologies such as $\mathrm{MR}$ in order to optimize his performance and further minimize mistakes, with the integration of collaborative robots. Even a simple human task is difficult for a cobot to perform because a human operator must make numerous decisions, both consciously and subconsciously, before performing such a task. They will assess the need for assistance, assess the risk of providing assistance, keep an eye out for safety issues, and then safely approach to offer assistance. By the time cobots will work with humans in the presence of other humans and machines, they will need to have similar decision-making mechanisms built into their systems, which will necessitate advanced perception, localization, vision, and cognition abilities, as well as increased computation power in embedded platforms. The current trends in DL, ML, and embedded systems suggest that further advancements in these fields will greatly contribute towards achieving the required capabilities for a cobot. DL methods have recently demonstrated promising results in the fields of robotics and computer vision. These techniques have given robots and intelligent machines reliable cognition and visualization, which is critical in autonomous applications, such as cobots. Artificial Neural Networks with many layers in their structure are the foundation of DL strategies. The main advantage of DL algorithms is that as the amount of training data increases, they perform much better than traditional learning methods. More specifically, the more training data sets, the more effective DL methods become. The performance efficiency of DL techniques improves as the amount of training data increases, whereas the performance of traditional learning methods can become saturated if the training data exceeds the optimum level. At this point, it is stressed out that the optimal volume of Big Data Sets is an aspect requiring careful design by engineers, depending on the field of application, the algorithms implemented, the level of detail required etc..

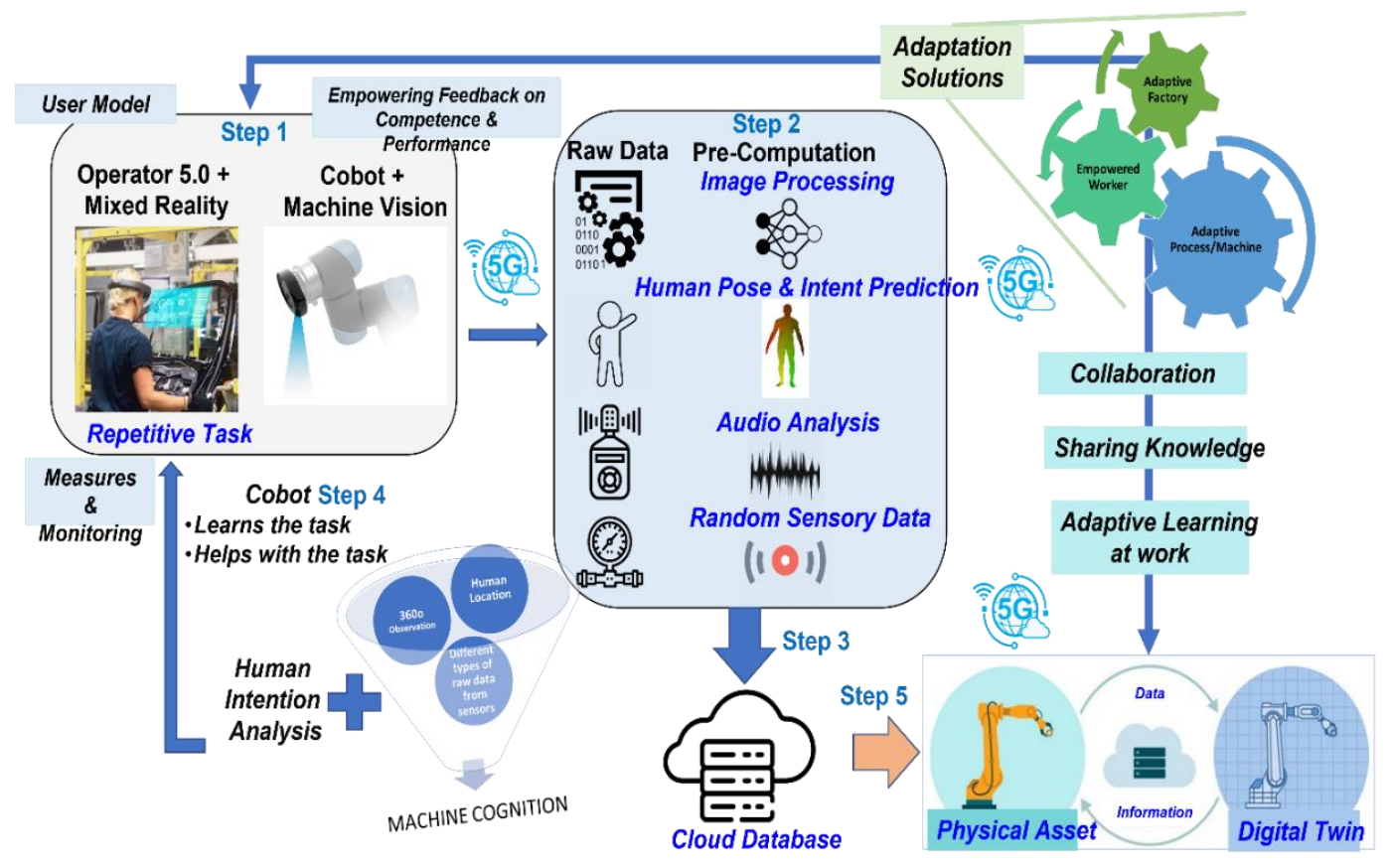

Fig. 14. Conceptual framework for Operator 5.0 and Cobot in Industry 5.0 
In Fig. 13 we have presented a conceptual framework for enabling the transition from Operator 4.0 to Operator 5.0. The proposed framework is based on the utilization of several cutting-edge digital technologies such as Mixed Reality (MR), Machine Vision, Cloud Manufacturing, Digital Twins, 5G Network and Data Analysis techniques. The main differentiation of this framework versus the other frameworks found in the literature, is the combination/integration of such technologies in order to combine the human intelligence with the machine's accuracy and high repeatability level.

Even though technology is driving the transition to Industry 5.0, this is not solely a technological revolution. When the technical system in the workplace changes, the social (or human) system changes as well, and vice versa. Work organization is said to be one of the most difficult aspects of implementing Industry 5.0.

\subsection{REQUIRED KNOWLEDGE - SKILLS FOR OPERATOR 5.0}

Based on the insights of the abovementioned Sections, it can be concluded that for operators working in factories that are adopting Industry 4.0, a certain level of knowledge is required. Furthermore, the required knowledge has to be of high level. However, as the advances in digital technologies are rapid, the operators should be re-skilled or up skilled in order to be able to handle edge connectivity, cloud solutions, and microservices, that are just a few of the modern technologies that are available to support the Fourth Industrial Revolution and beyond. Certain requirements must also be met, such as the ability to connect a production machine and the availability of process and production sensors. Additionally, due to the fact that operators, rather than developers or designers, are the first users of industrial products, they are one of the most important factors supporting the Fourth Industrial Revolution. As a result, the operator will need to be rehabilitated and trained for that purpose. As such, the required knowledge and skills can be achieved through the following:

- Basic knowledge of programming.

- Web development.

- Problem solving.

- Knowledge of the pillar technologies of Industry 4.0 and more specifically simulation and digital twins.

- Combination and usage of the data derived from the "Traditional HMI", the real time monitoring and provision to Machine Learning algorithms.

- Working with Information Technology (IT) solutions such as Manufacturing Execution Systems (MES).

- Knowledge of Programmable Logic Controller (PLC), instrumentation, process control, and automation.

- Knowledge of data science activities is required. Data analysis, descriptive analysis, and problem solving are characteristic examples.

- Mastering the English language, which is necessary for operators to take full advantage of Industry 4.0 tools and solutions. 
- IT literacy is a requirement for operators who want to use Industry 4.0 tools and solutions.

- Without being an Industry 4.0 developer, good understanding of how to work with and use Industry 4.0 tools is required.

\section{CONCLUSIONS \& OUTLOOK}

Within the context of Industry 4.0, human work has already and will continue to undergo important transformations. Along with the development of the necessary technological infrastructure for this transformation, technicians' performance and the adoption and integration of these new technologies are important areas of research. AR and human-robot collaboration seem to be the two main technologies studied in literature in relation to Operator 5.0. Additionally, manufacturing systems and strategies have evolved over time to increase productivity and efficiency, as evidenced by previous industrial revolutions. Accepting the next industrial revolution (Industry 5.0), on the other hand, necessitates the adoption, standardization, and implementation of new technologies, all of which require their own infrastructure and developments. Industry 5.0 will bring unprecedented challenges in the field of human-machine interaction (HMI), as machines will become increasingly integrated into people's daily lives. Wherever possible, Industry 5.0 will revolutionize manufacturing systems around the world by removing boring, dirty, and repetitive tasks from human technicians. Intelligent robots and systems will have unprecedented access to manufacturing supply chains and production floors. To do so in light of Industry 5.0 the following three pillars have to be considered as assisting parameters: three main characteristics: 1) humancentricity, 2) (social) sustainability, and 3) resilience [91].

As it regards the "Resilient Operator 5.0", this paper identified the pillar technologies for the new era of operator and has also provided a human-centric, socially sustainable, and resilient vision for the future of work in smart resilient manufacturing systems. Additionally, the evolution from the Operator 4.0 vision towards Operator 5.0 aims to build trusting relationships (interaction-based) between humans and machines (including automation, robotics, and AI systems), allowing truly smart resilient manufacturing systems to capitalize not only on smart machines' strengths and capabilities, but also to empower their smart operators with new skills and gadgets for the new working paradigm called "humanautomation symbiosis" [44].

\section{REFERENCES}

[1] MOURTZIS D., DOUKAS M., 2014, The Evolution of Manufacturing Systems: from Craftsmanship to the Era of Customization, in Handbook of Research on Design and Management of Lean Production Systems, 1-29. IGI Global.

[2] ELMARAGHY H., MONOSTORI L., SCHUH G., ELMARAGHY W. 2021., Evolution and Future of Manufacturing Systems, CIRP Annals, 70/2, 635-658.

[3] BATCHELOR R., 1994, Henry Ford, Mass Production, Modernism, and Design (Vol. 1). Manchester University Press. 
[4] ALIZON F., SHOOTER S.B., SIMPSON T.W., 2008, Henry Ford and the Model T: Lessons for Product Platforming and Mass Customization, In International Design Engineering Technical Conferences and Computers and Information in Engineering Conference, 43291, 59-66.

[5] CHRYSSOLOURIS G., 2013, Manufacturing Systems: Theory and Practice, Springer Science \& Business Media.

[6] ROMERO D., BERNUS P., NORAN O., STAHRE J., FAST-BERGLUND A., 2016, The Operator 4.0: Human Cyber-Physical Systems \& Adaptive Automation Towards Human-Automation Symbiosis Work Systems, IFIP International Conference on Advances, Production Management Systems, Springer, Cham, 677-686.

[7] MATTSSON S., FAST-BERGLUND A., LI D., THORVALD P., 2020, Forming a Cognitive Automation Strategy for Operator 4.0 in Complex Assembly, Computers \& Industrial Engineering, 139, 105360.

[8] ROMERO D., WUEST T., STAHRE J., GORECKY D., 2017, Social Factory Architecture: Social Networking Services and Production Scenarios Through the Social Internet of Things, Services and People for the Social Operator 4.0, IFIP Advances in Information and Communication Technology, 513, 265-273.

[9] TORRES M.Y., NADEAU, S., 2020, Operator 4.0 In Manufacturing: Trends, Potential Technologies and Future Perspectives, Conference: Frühjahrskongress der Gesellschaft für Arbeitswissenschaft, March 16-18, At: Berlin, Germany.

[10] WORLD ECONOMIC FORUM, 2020, The Future of Jobs Report 2020, Geneva: World Economic Forum.

[11] VOGEL-HEUSER B., HESS D., 2016, Guest Editorial: Industry 4.0-Prerequisites and Visions, IEEE Trans. Autom. Sci. Eng., 13/2, 411-413.

[12] BAUERNHANS T., VOGEL-HEUSER B., TEN HOMPEL M., 2017, Allgemeine Grundlagen, Handbuch Industrie 4.0 Bd.4. Springer, ISBN: 978-3-662-53254-53256.

[13] VOGEL-HEUSER B., BAYRAK G., FRANK U., 2012, Forschungsfragen in "Produktionsautomatisierung der Zukunft”, Diskussionspapier für die acatech Projektgruppe ProCPS - Production CPS, acatech Materialien, Deutsche Akademie der Technikwissenschaften.

[14] KAGERMANN H., LUKAS W-D., WAHLSTER W., 2011, Industrie 4.0: Mit dem Internet der Dinge auf dem Weg zur 4. industriellen Revolution, VDI Nachrichten, http://www.vdi-nachrichten.com/Technik-Gesellschaft/Industrie40-Mit-Internet-Dinge-Weg-4-industriellen-Revolution.

[15] WANG S., WAN J., ZHANG D., LI D., ZHANG C., 2016, Towards Smart Factory for Industry 4.0: A SelfOrganized Multi-Agent System with Big Data Based Feedback and Coordination, Comput. Netw., 101, $158-68$.

[16] ZHONG R.Y., XU X., KLOTZ E., NEWMAN S.T., 2017, Intelligent Manufacturing in the Context of Industry 4.0: a Review, Engineering, 3/5, 616-30.

[17] BENOTSMANE R., KOVACS G., DUDAS L., 2019. Economic, Social Impacts and Operation of Smart Factories in Industry 4.0 Focusing on Simulation and Artificial Intelligence of Collaborating Robots, Social Scien., 8/5, 143.

[18] BREQUE M., DE NUL L., PETRIDIS A., 2021, Industry 5.0: Towards a Sustainable, Human-Centric and Resilient European Industry, Luxembourg, LU: European Commission, Directorate-General for Research and Innovation.

[19] EUROPEAN ECONOMIC AND SOCIAL COMMITTEE., 2021, Industry 5.0, Available online: https://ec.europa.eu/info/research-and-innovation/research-area/industrial-research-and-innovation/industry-50_en

[20] MOURTZIS D., 2021, Towards the 5th Industrial Revolution: A Literature Review and a Framework for Process Optimization Based on Big Data Analytics and Semantics, Journal of Machine Engineering, 21/3, 5-39.

[21] LONGO F., PADOVANO A., UMBRELLO S., 2020, Value-Oriented and Ethical Technology Engineering in Industry 5.0: a Human-Centric Perspective for the Design of the Factory of the Future, Appl Sci., 10/12, 4182.

[22] XU X., 2017, Machine Tool 4.0 for the New Era of Manufacturing, Int. J. Adv. Manuf. Technol. 92, $1893-1900$.

[23] LIU C., VENGAYIL H., ZHONG Y.R., XU X., 2018, A Systematic Development Method for Cyber-Physical Machine Tools, Journal of Manufacturing Systems, 48, 13-24.

[24] SCHÜTZE A., HELWIG N., SCHNEIDER T., 2018, Sensors 4.0-Smart Sensors and Measurement Technology Enable Industry 4.0, Journal of Sensors and Sensor systems, 7/1, 359-371.

[25] FLORES E., XU X., LU Y., 2020, Human Cyber-Physical Systems: A Skill-Based Correlation Between Humans and Machines, IEEE 16th International Conference on Automation Science and Engineering (CASE), $1313-1318$.

[26] MOURTZIS D., 2020, Machine Tool 4.0 in the Era of Digital Manufacturing, 32nd European Modeling \& Simulation Symposium, DOI: 10.46354/i3m.2020.emss.060.

[27] HWANG S.L., SALVENDY G., 1988, Operator Performance and Subjective Response in Control of Flexible Manufacturing Systems, Work \& Stress, 2/1, 27-39.

[28] ELMARAGHY H., MONOSTORI L., SCHUH G., ELMARAGHY W., 2021, Evolution and Future of ManufacTuring Systems, CIRP Annals, 70/2, 635-658.

[29] SHARIT J., SALVENDY G., 1982, External and Internal Intentional Environments II. Reconsideration of the Relationship Between Sinus Arrhythmia and Information Load, Ergonomics, 25/2, 121-132.

[30] HWANC S.L., BARFIELD W., CHANC T.C., SALVENDY G., 1984, Integration of Humans and Computers in the Operation and Control of Flexible Manufacturing Systems, International JoumaI of Production Research, 22, $841-856$. 
[31] PONSA ASENSIO P., VILANOVA R., AMANTE GARCIA, B., 2011. Human Intervention and Interface Design in Automation Systems, International Journal of Computers, Communications \& Control, 6/1, 166-174.

[32] REXROTH: A BOSCH COMPANY, 2022, First Connected Industry Line on-Stream in Daily Production, Available online at: https://www.boschrexroth.com/en/xc/trends-and-topics/industry-4-0/best-practices/multiproduct-line-demonstrator/homburg-assembly-line/homburg-line (Accessed on 03/03/2022).

[33] SYLLA N., BONNET V., COLLEDANI F., FRAISSE P., 2014, Ergonomic Contribution of ABLE Exoskeleton in Automotive Industry, Int. J. of Industrial Ergonomics, 44/4, 475-481.

[34] SATISFACTORY (A Collaborative and Augmented-Enabled Ecosystem for Increasing Satisfaction and Working Experience in Smart FACTORY Environments), http://satisfactory-project.eu/.

[35] VFF (Holistic, extensible, scalable and standard Virtual Factory Framework), http://www.vff-project.eu/.

[36] MYERS K., BERRY P., BLYTHE J., CONLEY K., GERVASIO M., MCGUINNESS D.L., et al., 2007, An Intelligent Personal Assistant for Task and Time Management, AI Magazine, 28/2, 47-61.

[37] LIAA (Lean Intelligent Assembly Automation), http://www.project-leanautomation.eu/.

[38] WUEST T., HRIBERNIK K., THOBEN K.-D., 2012, Can a Product Have a Facebook? A New Perspective on Product Avatars in Product Lifecycle Management, Rivest, L., Bouraz, A. \& Louhichi, B. (Eds.), PLM 2012, IFIP AICT 388, Heidelberg Berlin, Springer, 400-410.

[39] WUEST T., WEIMER D., IRGENS C., THOBEN K.-D., 2016, Machine Learning in Manufacturing: Advantages, Challenges and Applications, Production \& Manufacturing Research, 4/1,

[40] GAZZANEO L., PADOVANO A., UMBRELlO S., 2020, Designing Smart Operator 4.0 For Human Values: Value Sensitive Design Approach, Procedia Manufacturing, 42, 219-226.

[41] ROMERO D., WUEST T., KEEPERS M., CAVUOTO L.A., MEGAHED F.M., 2021, Smart Wearable and Collaborative Technologies for the Operator 4.0 in the Present and Post-COVID Digital Manufacturing Worlds, ASTM International, 5/1, Coden: SSMSCY.

[42] GORECKY D., SCHMITT M., LOSKYLL M., ZÜHLKE D., 2014, Human-Machine-Interaction in the Industry 4.0 Era, 12th IEEE International Conference on Industrial Informatics, 289-294.

[43] HANCOCK P.A., JAGACINSKI R.J., PARASURAMAN R., WICKENS C.D., WILSON G.F., KABER, D.B., 2013, Human-Automation Interaction Research: Past, Present and Future, Ergonomics in Des. 21/2, 9-14.

[44] KASSNER L., HIRMER P., WIELAND M., STEIMLE F., KÖNIGSBERGER J., MITSCHANG B., 2017, The Social Factory: Connecting People, Machines and Data in Manufacturing for Context Aware Exception Escalation, Proceedings of the 50th Hawaii International Conference. on System Sciences, 1673-1682.

[45] BAYGIN M., YETIS H., KARAKOSE M., AKIN E., 2016, Effect Analysis of Industry 4.0 to Higher Education, Proceedings of the 15th International Conference on Information Technology Based Higher Education and Training (ITHET), Istanbul, Turkey, IEEE, 1-4, 16502968.

[46] MOURTZIS D., PANOPOULOS N., ANGELOPOUlOS J., ZYGOMALAS S., DIMITRAKOPOULOS, G., STAVROPOULOS P., 2021, A Hybrid Teaching Factory Model for Supporting the Educational Process in COVID19 Era, Procedia CIRP, 104, 1626-1631.

[47] PERERA C., LIU C.H., JAYAWARDENA S., 2015, The Emerging Internet of Things Marketplace from an Industrial Perspective: A Survey, IEEE Trans. Emerg. Top. Comput. 3/4, 585-598.

[48] ROMERO D., NORAN O., STAHRE J., BERNUS P., FAST-BERGLUND A., 2015, Human Cyber-Physical Systems and Adaptive Automation Towards Human-Automation Symbiosis Work Systems, Nääs S. (ed.), APMS, IAICT, 488, 677-686, Springer, Cham, DOI: 10.1007/978-3-319-22759-7_64.

[49] ROMERO D., NORAN O., STAHRE J., BERNUS P., FAST-BERGLUND A., 2015, Towards a Human-Centred Reference Architecture for Next Generation Balanced Automation Systems: Human-Automation Symbiosis, Umeda S., Nakano M., Mizuyama H., Hibino H., Kiritsis D., Cieminski G. (eds.), APMS, IAICT, 460, 556-566, Springer, Cham, DOI: 10.1007/978-3-319-22759-7_64.

[50] ZHANG C., XI J., YANG X., 2008, An Architecture for Intelligent Collaborative Systems Based on Multi-Agent, 12th International Conference on CSCWD, 10042669, Xi'an, China, DOI: 10.1109/CSCWD.2008.4537008.

[51] INAGAKI T., 2003, Adaptive Automation: Sharing and Trading of Control, Handb. Cogn. Task Des., 8, $147-169$.

[52] RUTH K., ITO Y., 2018, Flexible-Intelligent and Smart Factory Systems, MTEF Research Guide, 1, Machine Tool Engineering Foundation, Available at: https://www.kousakukikai-zaidan.or.jp/en/.

[53] DOLGUI A., IVANOV D., PERON M., SGARBOSSA F., 2022, Expected Trends in Production Networks for Mass Personalization in the Cloud Technology Era, Design and Operation of Production Networks for Mass Personalization in the Era of Cloud Technology, 13-37.

[54] MOURTZIS D., 2022, The Mass Personalization of Global Networks, Design and Operation of Production Networks for Mass Personalization in the Era of Cloud Technology, 79-116.

[55] MOURTZIS D., ANGELOPOULOS J., PANOPOULOS N., 2021, Robust Engineering for the Design of Resilient Manufacturing Systems, Applied Sciences, 11/7, 3067, https://doi.org/10.3390/app11073067. 
[56] HOLLNAGEL E.P., 2011, The Scope of Resilience Engineering, Resilience Engineering in Practice: Guidebook A., Hollnagel E., et al. (Eds.), 2011, Aldershot, UK: Ashgate.

[57] KUSIAK A., 2020, Open Manufacturing: A Design-for-Resilience Approach, Production Research, 58/15, 46474658.

[58] ROMERO D., STAHRE J., et al., 2016, Towards an Operator 4.0 Typology: A Human-Centric Perspective on the Fourth Industrial Revolution Technologies, 46th International Conference on Computers and Industrial Engineering, October 29-31, Tianjin, China.

[59] ROMERO D., STAHRE J., 2021, Towards the Resilient Operator 5.0: The Future of Work in Smart Resilient Manufacturing Systems, Procedia CIRP, 104, 1089-1094.

[60] JOHANSSON B., FASTH A., STAHRE J. et al., 2009, Enabling Flexible Manufacturing Systems by Using Level of Automation as Design Parameter, Winter Simulation Conference, IEEE, December 13-16, Austin, Texas, US.

[61] RAMDASI P., RAMDASI P., 2018, Industry 4.0: Opportunities for Analytics, IEEE PuneCon, Pune, India, 1-5.

[62] MADNI A.Z., JACKSON S., 2009, Towards a Conceptual Framework for Resilience Engineering, IEEE Systems Journal, 3/2, 181-191.

[63] NAHAVANDI S., 2019, Industry 5.0 - A Human-Centric Solution, Sustainability, 11/16, 4371.

[64] UEDA K., 1992, An Approach to Bionic Manufacturing Systems Based on DNA-Type Information, Proc. of the ICOOMS'92, 303-308.

[65] MALSHE A., RAJURKAR K., SAMANT A., NOERGAARD-HANSEN H., BAPAT S., JIANG W., 2013, Bioinspired Surfaces for Advanced Applications, CIRP Annals, 2/2, 607-628.

[66] BYRNE G., DIMITROV D., MONOSTORI L., TETI R., VAN HOUTEN F., WERTHEIM R., 2018, Biologicalisation: Biological Transformation in Manufacturing, CIRP Journal of Manufacturing Science and Technology, 21, 1-32.

[67] WEGENER K., WEIKERT S., MAYR J., MAIER M., ALI AKBARI V.O., POSTEL M., 2021, Operator Integrated-Concept for Manufacturing Intelligence, Journal of Machine Engineering, 21/4, 5-28.

[68] SOWE S.K., SIMMON E., ZETTSU K., DE VAULX F., BOJANOVA I., 2016, Cyber-Physical-Human Systems: Putting People in the Loop, IT Professional, 18/1, 10-13.

[69] ZHOU J., ZHOU Y., WANG B., ZANG J., 2019, Human-Cyber-Physical Systems (Hcpss) in The Context of NewGeneration Intelligent Manufacturing, Engineering, 5/4, 624-636.

[70] PATHAK P., PAL P.R., SHRIVASTAVA M., ORA P., 2019, Fifth Revolution: Applied Ai \& Human Intelligence with Cyber Physical Systems, International Journal of Engineering and Advanced Technology, 8/3, 23-27.

[71] XU X., LU Y., VOGEL-HEUSER B., WANG L., 2021, Industry 4.0 and Industry 5.0-Inception, Conception and Perception, Journal of Manufacturing Systems, 61, 530-535.

[72] WANG L., 2022, A Futuristic Perspective on Human-Centric Assembly, Journal of Manufacturing Systems, 62, 199-201.

[73] MOURTZIS D., MILAS N., ATHINAIOS N., 2018, Towards Machine Shop 4.0: A General Machine Model for CNC Machine-Tools Through OPC-UA, Procedia CIRP, 78, 301-306.

[74] MOURTZIS D., 2020, Simulation in the Design and Operation of Manufacturing Systems: State of the Art and New Trends, International Journal of Production Research, 58/7, 1927-1949.

[75] TAO F., ZHANG H., LIU A., NEE A.Y., 2018, Digital Twin in Industry: State-of-the-Art, IEEE Transactions on Industrial Informatics, 15/4, 2405-2415.

[76] MOURTZIS D., MILAS N., VLACHOU A., 2018, An Internet of Things-Based Monitoring System for Shop-Floor Control, Journal of Computing and Information Science in Engineering, 18/2, 021005, DOI: 10.1115/1.4039429.

[77] MOURTZIS D., ANGELOPOULOS J., PANOPOULOS N., 2021, Development of a Teaching Factory Framework Fusing a Virtual Simulated Machine Shop with the Physical Counterpart for Upscaling Human Machine Interface, Available at SSRN, 3859139.

[78] BIBEL W., 2010, General Aspects of Intelligent Autonomous Systems. Pratihar D.K., Jain L.C. (eds), Intelligent Autonomous Systems, Studies in Computational Intelligence, 275. Springer, Berlin, Heidelberg. DOI: 10.1007/9783-642-11676-6_2.

[79] WICKENS C.D., HOLLANDS J.G., BANBURY S., PARASURAMAN R., 2015, Engineering Psychology \& Human Performance, Psychology Press, Hove, UK.

[80] GOODRICH M.A., SCHULTZ A.C., 2008, Human-Robot Interaction: A Survey, Found, Trends Hum. Comput. Interact. 1, 203-275.

[81] HOSSNY M., NAHAVANDI S., CREIGHTON D., BHATTI A., 2010, Image Fusion Performance Metric Based on Mutual Information and Entropy Driven Quadtree Decomposition, Electron. Lett., 46, 1266-1268.

[82] SALEH K., HOSSNY M., NAHAVANDI S., 2018, Intent Prediction of Pedestrians via Motion Trajectories Using Stacked Recurrent Neural Networks, IEEE Trans. Intell. Veh., 3, 414-424.

[83] ABOBAKR A., HOSSNY M., NAHAVANDI S., 2018, A Skeleton-Free Fall Detection System from Depth Images Using Random Decision Forest, IEEE Syst. J. 2018, 12, 2994-3005. 
[84] MILLER C.C., 2017, Evidence That Robots are Winning the Race for American Jobs, Available online: https://www.nytimes.com/2017/03/28/upshot/evidence-that-robots-are-winning-the-race-for-american-jobs.html.

[85] SUTHERLAND I.E., 1968, A Head-Mounted Three Dimensional Display, Proc. Fall Joint Comput. Conf., Dec., 757-764, DOI: 10.1145/1476589.1476686.

[86] FAST-BERGLUND A., GONG L., LI D., 2018, Testing and Validating Extended Reality (Xr) Technologies in Manufacturing, Procedia Manuf., 25, 31-38.

[87] MILGRAM P., TAKEMURA H., UTSUMI A., KISHINO F., 1994, Augmented Reality: A Class of Displays on the Reality-Virtuality Continuum, SPIE Proceedings, Telemanipulator and Telepresence Technologies, Boston, MA.

[88] AZUMA R.T., 1997, A Survey of Augmented Reality, Teleoperators \& Virtual Environments, 6/4, 355-385.

[89] MOURTZIS D., ANGELOPOULOS J., PANOPOULOS N., 2020, A Framework for Automatic Generation of Augmented Reality Maintenance \& Repair Instructions Based on Convolutional Neural Networks, Procedia CIRP, 93, 977-982.

[90] GONG L., FAST-BERGLUND A., JOHANSSON B., 2021, A Framework for Extended Reality System Development in Manufacturing, IEEE Access, 9, 24796-24813.

[91] EUROPEAN COMMISSION, 2021, Industry 5.0: Towards a Sustainable, Human- Centric and Resilient European Industry, URL: https:/op.europa.eu/en/publication-detail/-/publication/468a892a-5097-11eb-b59f-01aa75ed71a 1. 